\title{
Effect of the Rock Stress on the Water Jet Cutting Performance
}

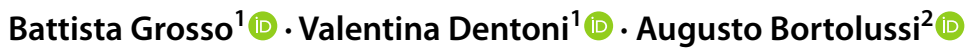

Received: 28 September 2020 / Accepted: 8 May 2021 / Published online: 6 June 2021

(c) The Author(s) 2021

\begin{abstract}
Underground quarrying is rarely adopted for granite extraction due to the difficulties in the implementation of traditional technologies (drilling and explosive). As alternative to drilling and explosive, the combination of diamond wire and water jet seems to be the most promising available technology. The cutting performance achievable with the water jet technology depends on the operative parameters, the material characteristics and the state of stress within the rock massif. To assess the effect of the state of stress on the cutting rate, laboratory tests have been performed with an oscillating water jet machine on granite samples subjected to a static load. The stress distribution in the layer of rock to be removed has been evaluated by numerical simulation with the FLAC code (Fast Lagrangian Analysis of Continua). The correlation between the results of the cutting tests and the numerical models of the rock samples has been inferred. Starting from a conceptual model, which theoretically describes the relationship between the cutting rate and the stress, a step function was defined that indicates the ranges of stress where predefined values of the cutting rate are workable.
\end{abstract}

Keywords Oscillating water jet $\cdot$ Water jet performance $\cdot$ Rock state of stress $\cdot$ Granite underground quarrying

\section{List of Symbols}

$\alpha \quad$ Angular amplitude of the lance oscillations $\left({ }^{\circ}\right)$

$\beta \quad$ Angle of the jet impact on the rock surface $\left({ }^{\circ}\right)$

$f \quad$ Lance oscillating frequency $(\mathrm{Hz})$

$S \quad$ Nozzle distance from the groove's bottom surface (mm)

$p \quad$ Water jet generation pressure $(\mathrm{Pa})$

SOD Stand off distance ( $\mathrm{mm}$ )

$v_{t} \quad$ Transverse velocity $(\mathrm{m} / \mathrm{min})$

a Advancement per cycle (mm)

$d \quad$ Deepening per cycle $(\mathrm{mm})$

CR Cutting rate $\left(\mathrm{m}^{2} / \mathrm{h}\right)$

CR* Predefined cutting rate $\left(\mathrm{m}^{2} / \mathrm{h}\right)$

ECR Equilibrium cutting rate $\left(\mathrm{M}^{2} / \mathrm{h}\right)$

$\sigma_{x x} \quad$ Normal stress component in $x$ direction $(\mathrm{Pa})$

Battista Grosso

grosso@unica.it

Valentina Dentoni

vdentoni@unica.it

Augusto Bortolussi

bortolussi@unica.it

1 Department of Civil and Environmental Engineering and Architecture, University of Cagliari, Cagliari, Italy

2 Institute of Environmental Geology and Geo-Engineering, National Research Council of Italy, Cagliari, Italy
$\Delta \sigma_{x x} \quad$ Normal stress interval $(\mathrm{Pa})$

$S \sigma_{x x} \quad$ Sustainability limit stress (Pa)

$E \sigma_{x x} \quad$ Efficiency limit stress (Pa

\section{Introduction}

Surface quarrying is the most common method to extract dimensional stones, due to the relatively low depth of the deposits, as well as to the objective difficulties in implementing traditional cutting technologies in underground environments. On the other hand, new constraints are progressively imposed by national and international environmental regulation which affect the overall economic balance of the industrial enterprise. As a matter of fact, underground quarrying appears to be better suited to modern trends, as it minimizes the temporary negative effects due to the project actions, such as noise (Bortolussi 2010) and emission of air pollutants (Particulate Matter, in particular), as well as the permanent effects of the quarry itself, among which land consumption and landscape alteration are the most significant (Dentoni 2020; Babitha 2007; Fugiel 2017).

At the present time, underground quarrying is widely diffused in the marble extraction industry, while it is rarely adopted for granite extraction (Fornaro 1992). In fact, while marble cutting technologies (wire and diamond saw) are suited both for surface and underground excavation, the 
technologies traditionally used for granite extraction (drilling and explosive) (Ashmole 2008) can be hardly implemented underground.

As alternative to drilling and explosive, granite slotting can be performed with the diamond wire machine, which yet needs the support of an another technology due to its inherent limitations: the combination of diamond wire and water jet seems to be the most promising solution, with the water jet playing the same role as the diamond saw in marble quarries (Ciccu and Fiamminghi 1996).

The use of the water jet technology in mining and quarrying has been proposed by many authors for its ability to reduce the production of dust, the temperature of the mechanical tools when hydro-mechanical excavation technologies are used and, in general, of extending mechanical excavation to the hard and abrasive rocks (Averin 2017; Hood 1993).

The experimental study hereby discussed is the development of a research program started before 2000, which has been implemented with new procedures and additional laboratory tests (Ciccu 2013); it specifically deals with the application of the oscillating water jet technology to underground extraction of granite and intends to investigate the correlation between the rock's state of stress and the water jet's cutting performance. In fact, some industrial experiences have demonstrated as the achievable slotting rate on a given type of rock depends on the state of stress within the rock massif (Stoxreiter 2018): it has been observed that in compressed rocks, the attainable cutting rate is lower than in unstressed rocks, whereas it is higher in rocks subjected to tensile stresses (Ciccu 1998).

This article reports the results of the cutting tests performed on granite samples of Rosa Beta quarried in Sardinia (Italy); three conditions have been investigated: unloaded samples (reference condition), samples subjected to compressive stress and samples subjected to tensile stress. The stress distribution in the layers of rock being cut has been modeled with the three-dimensional FLAC code, for the three experimental conditions under investigation. Two distinct yet complementary issues were taken into consideration: the relationship between the cutting rate and the state of stress within the rock and its dependence on the water jet energy.

\section{Underground Quarrying with Water Jet}

\subsection{Combination of Diamond wire and Water Jet}

A suitable diamond wire-water jet combination for underground extraction of granite is illustrated in Fig. 1, which shows the two phases of a cutting sequence aimed at

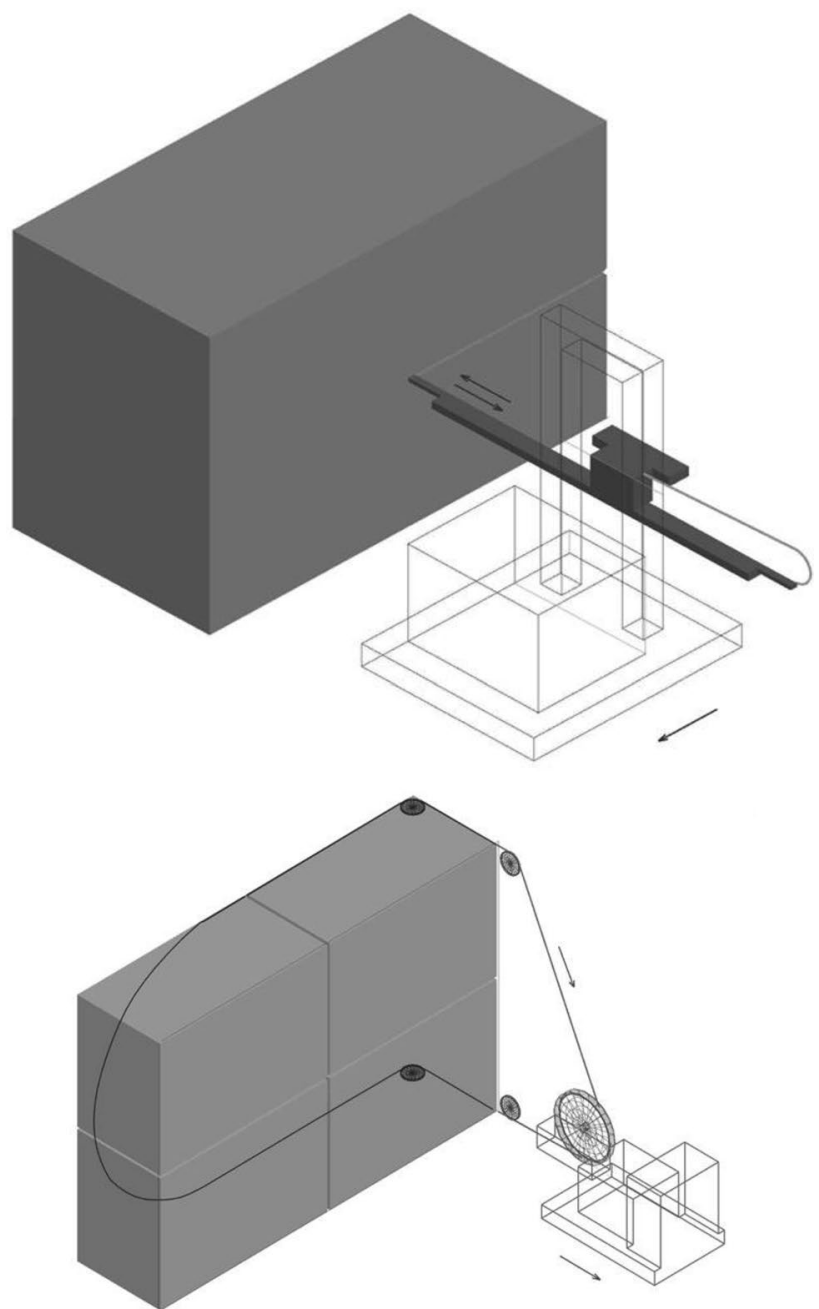

Fig. 1 Combined of water jet and diamond wire. First phase: water jet slotting of the side faces (slot depth: $3 \mathrm{~m}$ ). Second phase: diamond wire sawing of the back faces, in two stages (block width: $1.5 \mathrm{~m}$ )

isolating 8 commercial blocks. To cut the side faces of the blocks, a $3 \mathrm{~m}$ pilot hole is first drilled perpendicular to the front, from which a first slot can be started. The water jet lance, which supports and directs the nozzle towards the rock to be removed, moves forth and back, starting from the pilot hole and proceeding parallel to it. After each cycle (two strokes) the lance is moved sideways, by incremental steps, thus progressively extending the first slot's surface.

All subsequent slots can be started from the first, following a convenient order (first phase). Once all the side slots are completed, individual blocks can be extracted by cutting the back faces with the diamond wire machine (second phase): two vertical cuts in the example of Fig. 1 are required to obtain blocks of proper width $(1.5 \mathrm{~m})$. 


\subsection{Slotting with Oscillating Water Jet}

In the oscillating version of the water jet technology, the lance that holds the nozzle is animated by an oscillatory motion around its own axis (frequency $f$ and angular amplitude $\alpha$ ) and a transverse motion (velocity $v_{t}$ ) in the direction of the groove generated by the jet itself (in z-direction) (Reichman 1978). The nozzle is located at a given distance

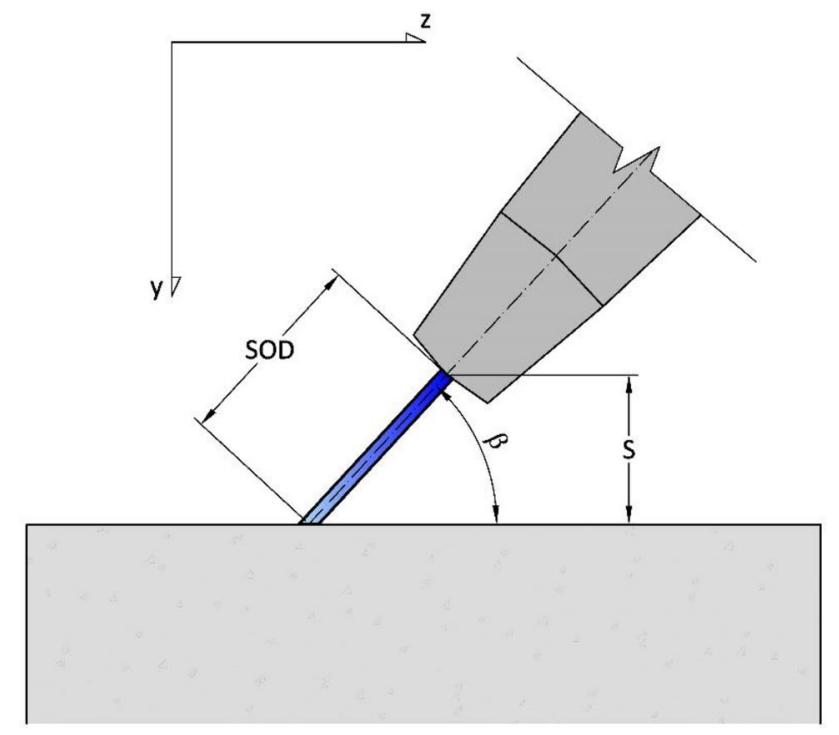

Fig. 2 Geometric parameters of the water jet in the yz plane

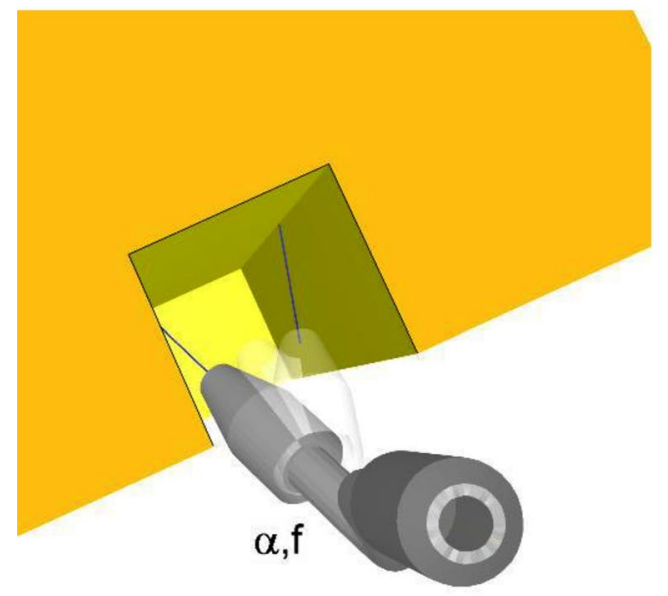

$S$ (in y-direction) from the groove's bottom surface, upon which the jet impacts with a fixed angle $\beta$ (the standoff distance is the distance from the nozzle to the jet impact point, along the direction defined by $\beta$ (Fig. 2)). A simplified 3D representation of the operating parameters above described is reported in Fig. 3.

The lance travels along the groove in both directions alternately: one cycle (two strokes) generates the increment $d$ of the groove depth (deepening); at each cycle the lance is approached to the groove's bottom by a distance $a$. The excavation performance is given by the areal cutting rate $C R$, which is the product of the lance's transverse velocity $v_{t}$ by the number of cycle in the unit of time by the lance's advancement $a$. The cut efficiency is expressed by the amount of energy required to remove the rock unit volume $\left(\mathrm{J} / \mathrm{cm}^{3}\right)$ (Summers 1991; Bortolussi 1992).

For a given rock and constant transverse velocity, the cut develops in steady conditions when the groove's deepening $d$ equals the lance's advancement $a$; under those conditions, the standoff distance ( $S O D$ ) remains constant (i.e., equal to the optimal set-up value). If the lance's transverse velocity is too high, the cut's deepening becomes lower than the lance's advancement and $S O D$ progressively decreases, until the lance collides with the bottom of the groove. If the lance's transverse velocity is too low, the cut deepening becomes greater than the lance's advancement and a progressive increase of $S O D$ occurs; this corresponds to a reduction of both the cutting efficiency and the cut's deepening, which goes on until $d$ equals $a$ again; from this point onwards, the

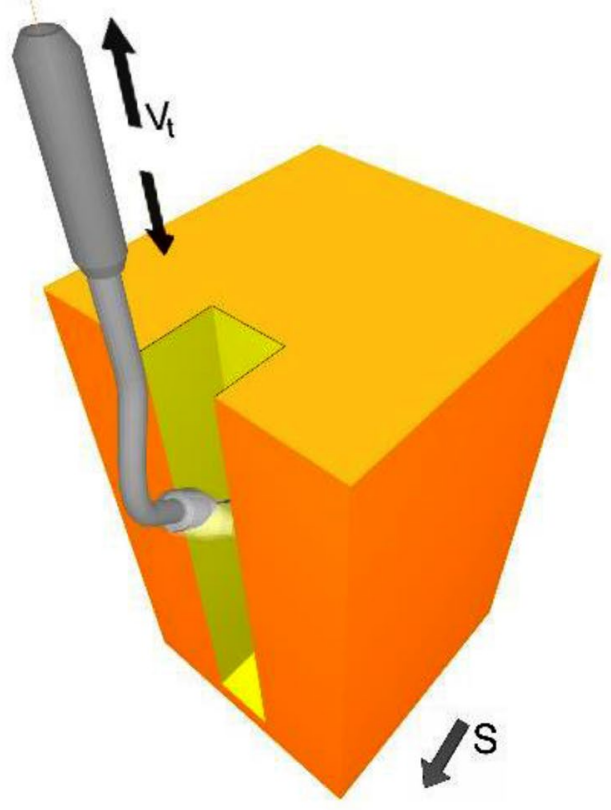

Fig. 3 Operating parameters of the oscillating water jet: frequency $f$ and angular amplitude $\alpha$ (lance's oscillating motion); velocity $v_{t}$ (lance's transverse motion); distance $\mathrm{S}$ from the nozzle to groove's bottom surface 
cut proceeds in steady conditions, with a $S O D$ greater than the optimum set-up value and both the efficiency and the cutting rate $C R$ lower than maximum attainable (Hood et al. 1990; Rehbinder 1977).

In compressed rocks, the reduction of the resisting crosssectional area due to the slot's development generates a progressive increase of the compressive stress acting at the groove's bottom and a corresponding progressive reduction in the cut's deepening $d$ : a geometric limit condition is reached, beyond which $d$ becomes less than $a$; from this point on, the continuation of the cut with the same transverse velocity can only take place by reducing the lance's advancement in accordance to the decrease of the cut's deepening, with a corresponding reduction of the cutting rate.

In tense rocks, the reduction of the resisting cross-sectional area due to the cut's advancement generates a progressive increase of the tensile stress acting at the groove's bottom and a corresponding progressive increase of the cut deepening, up to the limit beyond which $d$ becomes greater than $a$; from this point onwards, the continuation of the cut with the same transverse velocity and at the maximum efficiency requires the increasing of the lance's advancement, with corresponding increment of the cutting rate.

According to the forethoughts above, the stress limit condition is defined as that stress beyond which the maintenance of the optimal $S O D$ implies the modification of $C R$ : a reduction in case of compression stress and a raise in case of tensile stress. In compressed rocks and for a given CR, the stress limit condition represents the value of the stress up to which the rock can be cut and beyond which the CR must be reduced. In tense rocks and for a given CR, it represents the level of stress up to which the rock is cut with the maximum efficiency and beyond which the CR has to be increased to preserve the efficiency level.

It is worth noticing that $C R$ can be modified by adjusting either the lance's advancement $a$ or the lance's transverse velocity $v_{t}$. In the experimental test described in the following sections of the article, $C R$ has been modified by adjusting $v_{t}$ : higher values were used to reduce $C R$ and lower values to increase $C R$, with a fixed value of the lance's advancement $a$.

\subsection{State of Stress in Underground Quarrying}

In underground production of squared blocks, the first excavation phase consists in the opening of an entry tunnel, starting from the hillside, until the planned quarrying area is reached; then the tunnel is further enlarged leaving the pillars to support the roof. In case of thick deposits, the excavation can be further developed below the level of the access tunnel: a large chamber is progressively created by exploiting the rock layers with a downwards sequence.

The compression vertical component of the original stress acting in the rock can be quite high, depending of the tunnel depth; during the tunnel advancement, its value at the bottom of the horizontal grooves realized to extract the rock blocks is further increased as a result of the vertical stress redistribution. The same phenomenon occurs at the chambers' walls during their enlargement. As a result of the extraction of the first layer of the chamber (roof layer), the compression stress in the rock volume below is almost thoroughly relieved. Consequently, during the following cutting operations, the stress at the bottom of the grooves is significantly lowered.

Tensile states of stress typically occur at the chamber roof, as a function of the roof span and the ratio $(k)$ between the horizontal and vertical stress components $\left(k=\sigma_{\mathrm{h}} / \sigma_{\mathrm{v}}\right)$. In the typical geometric configurations of underground quarries it is rare to cut blocks subjected to tensile stress; on the other hand, based on the research results, tensile stress could be artificially generated to improve the water jet slotting performances.

\section{The Experimental Research}

\subsection{Rock Samples and Experimental Set-up}

Three series of cutting test have been performed on granite specimens of Rosa Beta quarried in Sardinia (Italy), first unstressed and then subjected to compression and tensile stresses, aimed at evaluating the stress limit condition at which a predefined cutting rate can be maintained. The experiments have been repeated for three jet generation pressure (100, 160 and $200 \mathrm{MPa}$ ).

The physical and mechanical properties of the granite samples are synthesized in Table 1.

The experimental set-up installed at the Water Jet laboratory of DICAAR (Department of Civil and Environmental Engineering and Architecture), in Cagliari University (Italy), consists of the following components:

- a Hammelmann High-Pressure plunger pump (power at the engine flywheel: about $300 \mathrm{~kW}$; maximum flowrate: $54 \mathrm{l} / \mathrm{min}$ at $250 \mathrm{MPa}$;

Table 1 Physical and mechanical properties of Rosa Beta granite

\begin{tabular}{ll}
\hline Property & Value \\
\hline Bulk specific gravity [kg/m3] & 2.588 \\
Absorption coefficient [\%] & 4.85 \\
Porosity [\%] & 0.63 \\
Compressive strength [MPa] & 192 \\
Flexural strength (MPa) & 156 \\
Impact test (Height of fall) [cm] & 68 \\
P-wave velocity [m/s] & 5626 \\
\hline
\end{tabular}


- an oscillating lance (top frequency: $f=20 \mathrm{~Hz}$; maximum traverse velocity $\left.v_{t}: 15 \mathrm{~m} / \mathrm{min}\right)$;

- a block carrier platform;

- a programmable lance control unit;

- a specially designed uniaxial compression cell provided with a hydraulic jack capable of imparting a load up to $100 \mathrm{t}$.

Table 2 reports the operative parameters of the oscillating water jet. Figure 4 represents the water jet lance and its slotting action on an unloaded sample.

\subsection{Test on Unloaded Samples}

The first test series has been performed on unloaded samples, aimed at assessing the reference cutting rate at the zero

Table 2 Water jet operative parameters

\begin{tabular}{ll}
\hline Parameter & Value \\
\hline Water jet generation pressure [MPa] & $100,160,200$ \\
Nozzle diameter $\Phi[\mathrm{mm}]$ & 0.96 \\
Stand - off distance SOD [mm] & 20 \\
Jet impact angle $\beta$ & $50^{\circ}$ \\
Oscillation frequency f [Hz] & $20 \mathrm{~Hz}$ \\
Sweeping angle $\alpha$ & $22^{\circ}$ on each side \\
Advancement per cycle [y-direction] $a[\mathrm{~mm}]$ & 2 \\
Transverse velocity [z-direction] $v_{t}[\mathrm{~m} / \mathrm{min}]$ & variable \\
\hline
\end{tabular}

stress condition. In this case, the deepening of the cut does not cause any change in the state of stress within the rock, so that $C R$ only depends on the material properties and the water jet operative parameters. The maximum value of $C R$ is estimated by adjusting the lance's transverse velocity as to obtain the equivalence between the cut's deepening $d$ and the lance's advancement $a$. Table 3 reports the experimental plan for the unloaded samples.

Table 3

\subsection{Test on Compressed Samples}

The second series of test has been carried out by subjecting the granite samples to an evenly distributed lateral compression, according to the scheme in Fig. 5: in that condition, the slot progress causes the increment of the compression stress in the layer of rock where the jet acts (grove's bottom), so that a progressive reduction of the cutting rate is required. Table 4 reports the succeeding values of the cutting rates

Table 3 Experimental plan for unloaded samples

\begin{tabular}{lllll}
\hline Test & Sample N & Load $(\mathrm{kN})$ & $\begin{array}{l}\text { Jet pressure } \\
p(\mathrm{MPa})\end{array}$ & $\begin{array}{l}\text { Advance- } \\
\text { ment } a \\
(\mathrm{~mm})\end{array}$ \\
\hline Z1 & Z1a, Z1b, Z1c & 0 & 100 & 2 \\
Z2 & Z2a, Z2b, Z2c & 0 & 160 & 2 \\
Z3 & Z3a, Z3b, Z3c & 0 & 200 & 2 \\
\hline
\end{tabular}

Fig. 4 Water jet lance (left) and slotting of an unloaded sample (right)
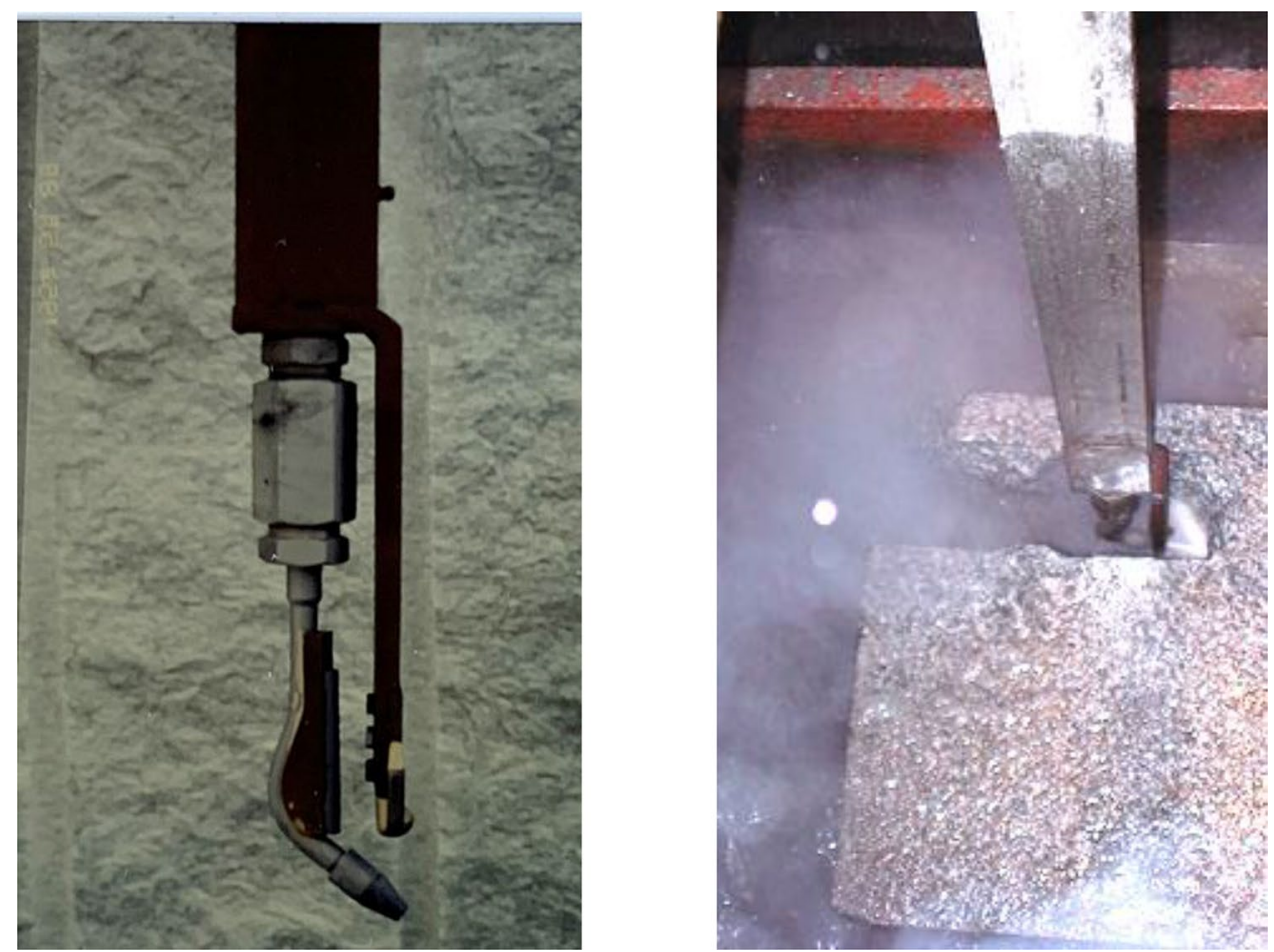


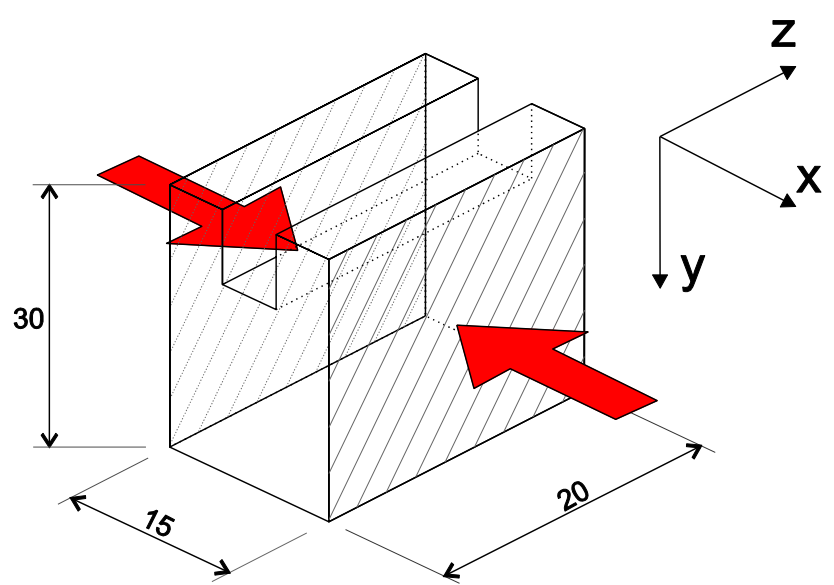

Fig. 5 Loading condition for testing compressed samples (dimensions in $\mathrm{cm}$ )

Table 4 Cutting rate steps for compressed samples

\begin{tabular}{ll}
\hline $\begin{array}{l}\text { Water jet generation pressure } \\
(\mathrm{MPa})\end{array}$ & $\begin{array}{l}\text { Cutting rate steps } \\
C R^{*} \\
\left(\mathrm{~m}^{2} / \mathrm{h}\right)\end{array}$ \\
\hline 100 & $0.45-0.36-0.30$ \\
160 & $1.30-1.10-0.90-0.85$ \\
200 & $1.79-1.78-1.75-1.65$ \\
\hline
\end{tabular}

$\left(\mathrm{CR}^{*}\right)$ to be adopted during the test, which were determined after some preliminary trials.

Aimed at evaluating the limit slot depth (i.e., maximum depth up to which a predetermined cutting rate $\mathrm{CR}^{*}$ can be maintained), the test starts at the highest suitable CR for a given water jet generation pressure (e.g., $0.45 \mathrm{~m}^{2} / \mathrm{h}$ with $p=100 \mathrm{MPa}$ ) and is then carried out to the depth at which a reduction of $S O D$ can be observed. To this purpose, at each stroke the lance is stopped and the distance between the nozzle and the mean plane of the slot bottom is measured. At that point, $\mathrm{CR}$ is lowered to the subsequent predefined value $\left(\mathrm{CR}^{*}=0.36 \mathrm{~m}^{2} / \mathrm{h}\right)$ and the cut continues until a new decrease of $S O D$ becomes apparent. Again CR is dropped to the lower consistent value $\left(\mathrm{CR}^{*}=0.30 \mathrm{~m}^{2 /} \mathrm{h}\right)$ to proceed with the cut on the same slot. The test ends when the limit slot depth is reached with the lowest CR* in the experimental plan. The procedure above described has been followed to perform the experimental test with applied lateral loads of 250 and $500 \mathrm{kN}$. Six granite samples were used for each jet generation pressure. The lance's advancement $a$ was fixed at $2 \mathrm{~mm}$ and the cutting rate was adjusted by modifying the lance's traverse velocity. The experimental plan for compressed samples is reported in Table 5.

\subsection{Test on Tense Samples}

With the third series of test, the alleged favorable effect of the tensile stress was investigated by applying a flexural load, as illustrated in Fig. 6. Two different load conditions were taken into consideration: $F=50 \mathrm{kN}$ and $F=100 \mathrm{kN}$ (total force acting on the sample), with a water jet generation pressure of $100 \mathrm{MPa}$. According to the experimental plan in Table 6, two cutting rates were selected for each load condition: 0.69 and $0.73 \mathrm{~m}^{2} / \mathrm{h}$ for $F=50 \mathrm{kN} ; 0.84$ and $1.0 \mathrm{~m}^{2} / \mathrm{h}$ for $F=100 \mathrm{kN}$. As for the case of compressed samples, the lance's advancement $a$ was kept unchanged ( $2 \mathrm{~mm}$ per cycle) and the cutting rate progressively adjusted by modifying the lance's transverse velocity $v_{t}$.

Because the progress of the slot causes a growth in the tensile stress, the cut is started at the predefined lowest value of $C R^{*}$ and continues until the first increment of $S O D$ is registered. The cutting rate is then raised up to the next step and the test continues.

\subsection{Test Results}

Test on the unloaded samples is meant to estimate the maximum obtainable cutting rate for each jet generation pressure ( $p=100,160,200 \mathrm{MPa}$ ). The resulting $C R s$ are assumed as reference values for the analysis of the alterations induced by the state of stress. For each water jet generation pressure, Table 7 reports the optimum values of the transverse velocity $v_{t}$ and the cutting rate $C R$, expressed as average of the three tests $(a, b, c)$.
Table 5 Experimental plan for compressed samples

\begin{tabular}{|c|c|c|c|c|c|c|}
\hline Test & Sample $\mathrm{N}^{\circ}$ & $\begin{array}{l}\text { Load } \\
(\mathrm{kN})\end{array}$ & $\begin{array}{l}\text { Jet pressure } \\
p \\
(\mathrm{MPa})\end{array}$ & $\begin{array}{l}\text { Traverse velocity } \\
v_{t} \\
(\mathrm{~m} / \mathrm{min})\end{array}$ & $\begin{array}{l}\text { Advance- } \\
\text { ment } \\
a \\
(\mathrm{~mm})\end{array}$ & $\begin{array}{l}\text { Cutting rate } \\
C R^{*} \\
\left(\mathrm{~m}^{2} / \mathrm{h}\right)\end{array}$ \\
\hline $\mathrm{C} 1$ & $\mathrm{C} 1 \mathrm{a}, \mathrm{C} 1 \mathrm{~b}, \mathrm{C} 1 \mathrm{c}$ & 250 & 100 & $3.75-3.0-2.5$ & 2 & $0.45-0.36-0.30$ \\
\hline $\mathrm{C} 2$ & $\mathrm{C} 2 \mathrm{a}, \mathrm{C} 2 \mathrm{~b}, \mathrm{C} 2 \mathrm{c}$ & 500 & 100 & $3.75-3.0-2.5$ & 2 & $0.45-0.36-0.30$ \\
\hline $\mathrm{C} 1{ }^{\prime}$ & $\mathrm{C} 1^{\prime} \mathrm{a}, \mathrm{C} 1^{\prime} \mathrm{b}, \mathrm{C} 1^{\prime} \mathrm{c}$ & 250 & 160 & $10.83-9.17$ & 2 & $1.30-1.10$ \\
\hline $\mathrm{C} 2{ }^{\prime}$ & $\mathrm{C} 2{ }^{\prime} \mathrm{a}, \mathrm{C} 2^{\prime} \mathrm{b}, \mathrm{C} 2^{\prime} \mathrm{c}$ & 500 & 160 & $7.50-7.08$ & 2 & $0.90-0.85$ \\
\hline $\mathrm{C} 1{ }^{\prime}$ & $\mathrm{C} 1$ '”, $\mathrm{C} 1$ '”, $\mathrm{C} 1$ '” & 250 & 200 & $14.9-14.8$ & 2 & $1.79-1.78$ \\
\hline $\mathrm{C} 2{ }^{\prime \prime}$ & $\mathrm{C} 2$ '’a, C2'’b, C2'”c & 500 & 200 & $14.6-13.7$ & 2 & $1.75-1.65$ \\
\hline
\end{tabular}




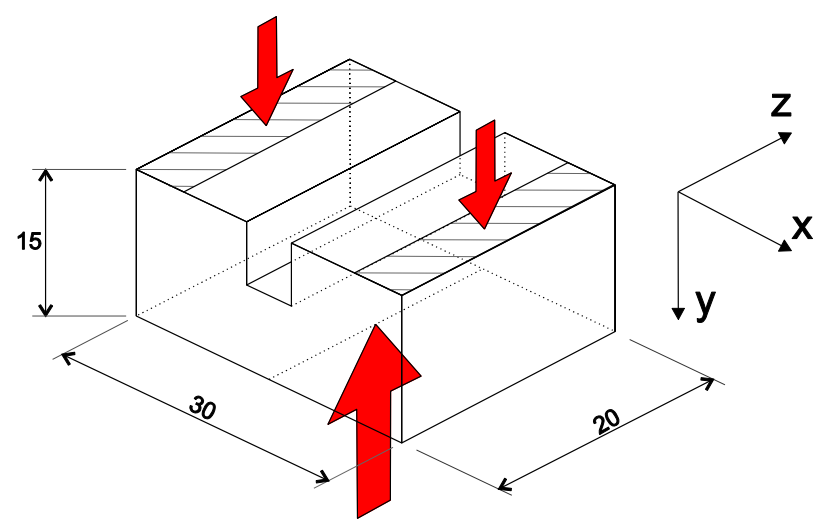

Fig. 6 Loading condition for testing tense samples (dimensions in $\mathrm{cm})$

Table 6 Experimental plan for tense samples

Table 7 Results of test on unloaded samples

Table 8 Results of test on compressed samples

\begin{tabular}{lllllll}
\hline & Sample $N^{\circ}$ & $\begin{array}{l}\text { Flexural } \\
\text { load }(\mathrm{kN})\end{array}$ & $\begin{array}{l}\text { Jet pressure } \\
p \\
(\mathrm{MPa})\end{array}$ & $\begin{array}{l}\text { Traverse velocity } \\
\boldsymbol{v}_{\boldsymbol{t}} \\
(\mathrm{m} / \mathrm{min})\end{array}$ & $\begin{array}{l}\text { Advance- } \\
\text { ment } \\
a \\
(\mathrm{~mm})\end{array}$ & $\begin{array}{l}\text { Cutting rate } \\
C R^{*} \\
\left(\mathrm{~m}^{2} / \mathrm{h}\right)\end{array}$ \\
\hline $\mathrm{T} 1$ & T1a T1b T1c & 50 & 100 & $5.75-6.08$ & 2 & $0.69-0.73$ \\
$\mathrm{~T} 2$ & T2a T2b T2c & 100 & 100 & $7.00-8.33$ & 2 & $0.84-1.00$ \\
\hline
\end{tabular}

\begin{tabular}{llllll}
\hline Test & Samples & $\begin{array}{l}\text { Jet pressure } \\
(\mathrm{MPa})\end{array}$ & $\begin{array}{l}\text { Traverse velocity } \\
v_{t} \\
(\mathrm{~m} / \mathrm{min})\end{array}$ & $\begin{array}{l}\text { Advance- } \\
\text { ment } \\
a\end{array}$ & $\begin{array}{l}\text { Cutting rate } \\
(\mathrm{mm})\end{array}$ \\
& & & $\begin{array}{l}C \mathrm{~m}^{*} \\
\left(\mathrm{~m}^{2} / \mathrm{h}\right)\end{array}$ \\
\hline Z1 & Z1a Z1b Z1c & 100 & $5.25=(5.5+4.9+5.2) / 3$ & 2 & 0.63 \\
Z2 & Z2a Z2b Z2c & 160 & $11.7=(11.0+12.5+11.5) / 3$ & 2 & 1.40 \\
& Z3a Z3b Z3c & 200 & $15.1=(14.8+15.0+15.3) / 3$ & 2 & 1.84 \\
\hline
\end{tabular}

\begin{tabular}{|c|c|c|c|c|c|}
\hline $\begin{array}{l}\text { Table } 8 \text { Results of test on } \\
\text { compressed samples }\end{array}$ & Test & $\begin{array}{l}\text { Jet pressure } p \\
\text { (MPa) }\end{array}$ & $\begin{array}{l}\text { Lateral load } \\
(\mathrm{kN})\end{array}$ & $\begin{array}{l}\text { Cutting rate } C R^{*} \\
\left(\mathrm{~m}^{2} / \mathrm{h}\right)\end{array}$ & Limit slot depth (mm) \\
\hline & \multirow[t]{3}{*}{$\mathrm{C} 1(\mathrm{a}, \mathrm{b}, \mathrm{c})$} & \multirow[t]{3}{*}{100} & \multirow[t]{3}{*}{250} & 0.45 & $25=(24.5+26+25) / 3$ \\
\hline & & & & 0.36 & $35=(36+33.5+35) / 3$ \\
\hline & & & & 0.30 & $60=(58+61+60.5) / 3$ \\
\hline & \multirow[t]{3}{*}{$\mathrm{C} 2(\mathrm{a}, \mathrm{b}, \mathrm{c})$} & \multirow[t]{3}{*}{100} & \multirow[t]{3}{*}{500} & 0.45 & $8=(7.5+9+8) / 3$ \\
\hline & & & & 0.36 & $15=(13.5+15+16) / 3$ \\
\hline & & & & 0.30 & $25=(27+25+24) / 3$ \\
\hline & \multirow[t]{2}{*}{$\mathrm{C} 1\left(\mathrm{a}^{\prime}, \mathrm{b}^{\prime}, \mathrm{c}^{\prime}\right)$} & \multirow[t]{2}{*}{160} & 250 & 1.30 & $23=(22.5+24+22) / 3$ \\
\hline & & & 250 & 1.10 & $61=(60+63+60.5) / 3$ \\
\hline & \multirow[t]{2}{*}{$\mathrm{C} 2\left(\mathrm{a}^{\prime}, \mathrm{b}^{\prime}, \mathrm{c}^{\prime}\right)$} & \multirow[t]{2}{*}{160} & 500 & 0.90 & $44=(45+44+42) / 3$ \\
\hline & & & 500 & 0.85 & $64=(63.5+65+64) / 3$ \\
\hline & \multirow[t]{2}{*}{$\mathrm{C} 1\left(\mathrm{a},{ }^{\prime}, \mathrm{b},, \mathrm{c}^{\prime \prime}\right)$} & \multirow[t]{2}{*}{200} & 250 & 1.79 & $40=(41+40+39) / 3$ \\
\hline & & & 250 & 1.78 & $65=(63.5+66+64) / 3$ \\
\hline & \multirow[t]{2}{*}{ C2 (a', b', c'”) } & \multirow[t]{2}{*}{200} & 500 & 1.75 & $65=(66+63+65) / 3$ \\
\hline & & & 500 & 1.65 & $82=(81+83+82.5) / 3$ \\
\hline
\end{tabular}

Test on compressed samples is meant to estimate the limit slot depths up to which the preset $C R^{*}$ can be maintained. The results of the experimental test on compressed samples are reported in Table 8, again in terms of mean value.

Test on samples subjected to tensile stress is meant to estimate the limit slot depths at which $C R^{*}$ must be increased, to maintain the original level of efficiency. Table 9 reports the results of the experimental test carried out on tense samples with a jet generation pressure of $100 \mathrm{MPa}$. In Fig. 7, an example of the grooves generated by the water jet is given.

\subsection{State of Stress Simulation}

The stress distribution in the layer of rock being cut (groove's bottom) has been analyzed using the three-dimensional FLAC (Fast Lagrangian Analysis of Continua) code. 
Table 9 Test on tenses samples- $\mathrm{p}=100 \mathrm{MPa}-$ Results

\begin{tabular}{llll}
\hline Test & $\begin{array}{l}\text { Flexural } \\
\text { load }(\mathrm{kN})\end{array}$ & $\begin{array}{l}\text { Cutting rate } \\
C R^{*} \\
\left(\mathrm{~m}^{2} / \mathrm{h}\right)\end{array}$ & Limit slot depth $(\mathrm{mm})$ \\
\hline $\mathrm{T} 1(\mathrm{a}, \mathrm{b}, \mathrm{c})$ & 50 & 0.69 & $5(4.5+6+5) / 3$ \\
$\mathrm{~T} 2(\mathrm{a}, \mathrm{b}, \mathrm{c})$ & 100 & 0.73 & $30(30.5+29.6+29.8) / 3$ \\
& & 0.84 & $30(30.1+29.2+30.7) / 3$ \\
& & 1.00 & $50(51+48.5+49) / 3$ \\
\hline
\end{tabular}

Two three-dimensional models were built, $\mathrm{CM}$ and TM, subjected to compressive and tensile stress, respectively. The spatial orientation of the models is set as follows:

$Z$-direction: axis of the slot.

$Y$-direction: depth of the slot.

$X$-direction: perpendicular to the slot plane.

The two models represent a $5 \mathrm{~cm}$ thick slice of the sample (along the z-direction), as indicated in Fig. 8. The stress acting in the volume removed by the water jet at each cycle is calculated as average of the normal components $\left(\sigma_{\mathrm{xx}}\right)$ acting on the elements of the calculation grid included in $2 \mathrm{~mm}$ of thickness (Fig. 9).

The rock material has been modeled as linear elastic, considering the physical and mechanical properties of Rosa Beta reported in Table 1. The state of stress was calculated for each of the experimental limit configurations (i.e.: experimental limit depths).

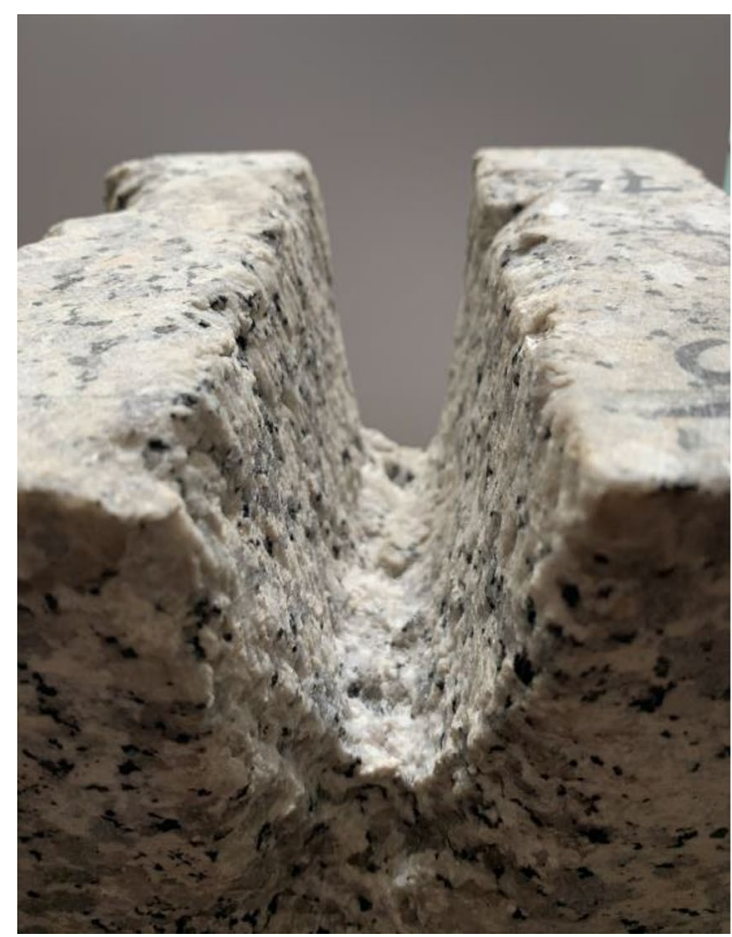

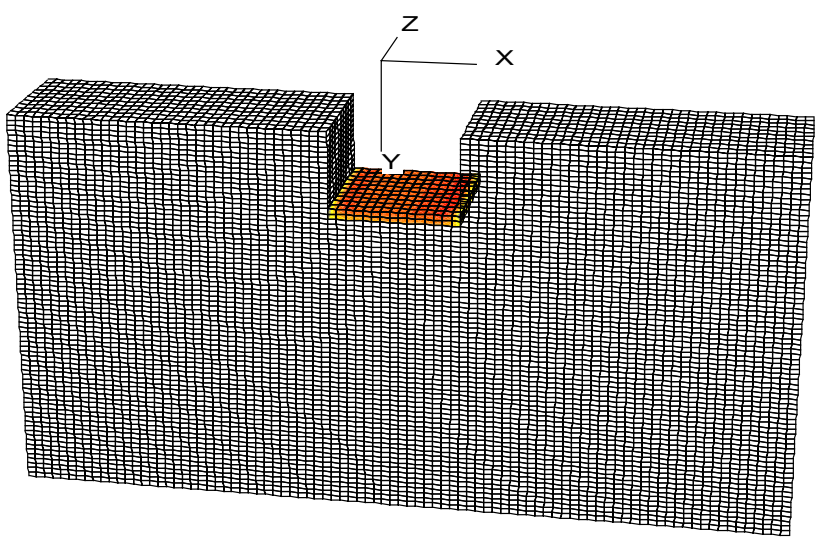

Fig. 8 Model geometry and identification of the elements in the layer of rock to be cut

\section{Discussion}

\subsection{Research Objective and Assumptions}

The experimental research hereby discussed is meant to define the dependence of the cutting rate $C R$ on the stress component $\sigma_{\mathrm{xx}}$ acting in the volume of rock to be removed. If, for a given value $\sigma_{\mathrm{xx}}$, the Equilibrium Cutting Rate ECR indicates the value of the cutting rate at which neither an increase nor a reduction of $S O D$ is observable, the continuous curve in Fig. 10 conceptually describes the relationship

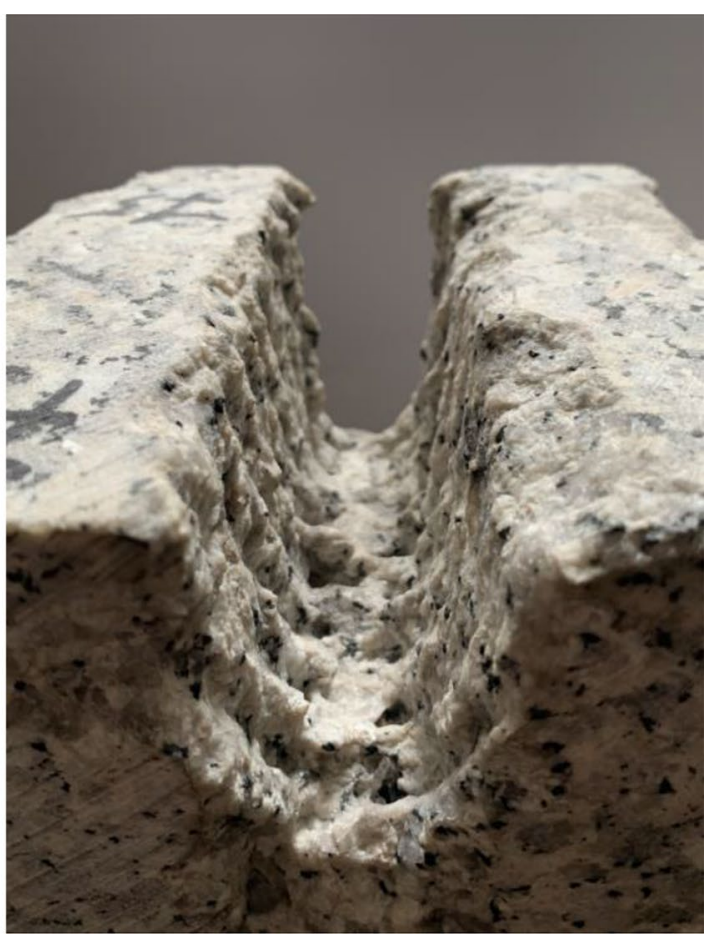

Fig. 7 Resulting grooves (about $5 \mathrm{~cm}$ wide) in loaded samples of Rosa Beta granite 


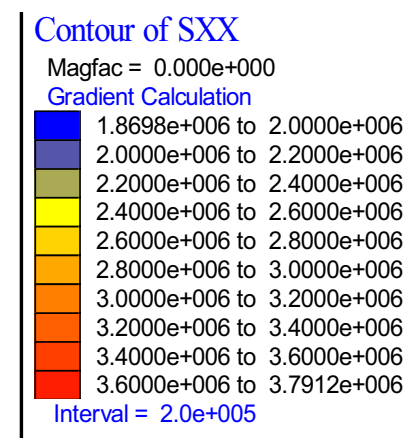

Fig. 9 Elements of the calculation grid included in $2 \mathrm{~mm}$ of thickness

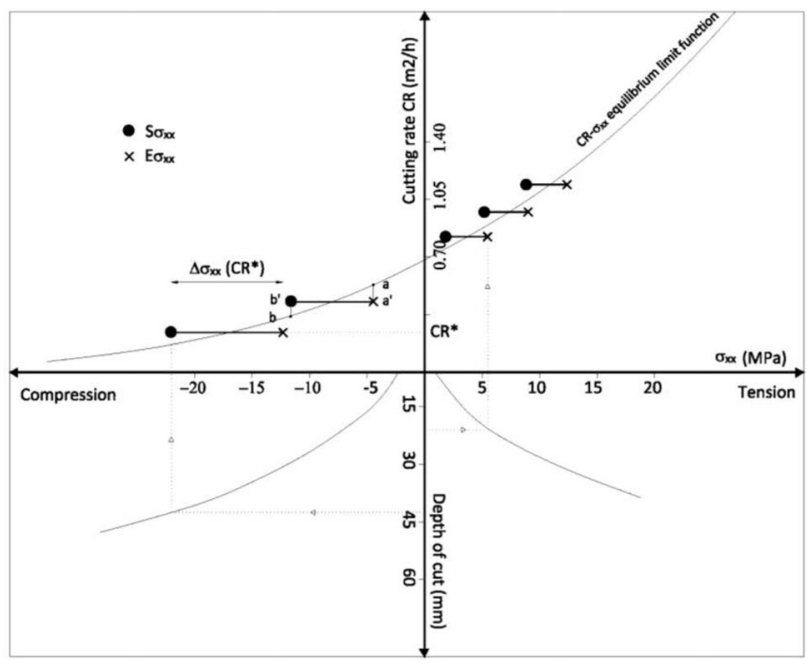

Fig. 10 Theoretical relationships $\sigma_{\mathrm{xx}}-$ Cutting rate $(\mathrm{CR})$ and $\sigma_{\mathrm{xx}}-\mathrm{Cut}-$ ting depth $(d)$

between the two variables, where each value of $E C R$ is related to one and only one value of $\sigma_{x x}$, i.e., given a value of $\sigma_{\mathrm{xx}}$ there is only one value of the CR for which the cut proceeds without variation of the SOD. Figure 10 also describes the theoretical relationship between the state of stress and the depth of the cut.

For a prearranged cutting rate $C R^{*}$, the experimental tests are meant to explore the range of $\sigma_{\mathrm{xx}}\left(\Delta \sigma_{\mathrm{xx}}\right)$ where the cutting proceeds without any appreciable variation of the stand-off distance $S O D$. Within that range, the difference between $C R^{*}$ and $E C R$ is not technically measurable. To this regard, in the adopted experimental procedure, the $\mathrm{CR}^{*}$ values have been set and the ranges of stress $\left(\Delta \sigma_{\mathrm{xx}}\right)$ in which they could be maintained have been investigated. In this ranges the preset values of the cutting rate $\left(\mathrm{CR}^{*}\right)$ can be technically assumed as ECR. The left limit of the range $\Delta \sigma_{x x}$ (higher value of compressive stress and lower value of tensile stress) represents the sustainability limit stress $\left(S \sigma_{x x}\right)$, beyond which a reduction of $C R$ is necessary to proceed with the slot (Fig. 10). The right limit of the range $\Delta \sigma_{x x}$ (lower value of compressive stress and higher value of tensile stress) is the efficiency limit stress $\left(E \sigma_{x x}\right)$, beyond which an increase of CR is necessary to maintain the maximum cutting efficiency. In practical applications, in fact, the continuous theoretical curve $\sigma_{\mathrm{xx}}-E C R$ in Fig. 10 becomes a step function, which indicates the range of $\sigma_{\mathrm{xx}}$ where a given $C R^{*}$ is workable: the width of the steps is $\Delta \sigma_{\mathrm{xx}}$, the height is twice the appreciable value of the difference $E C R-C R^{*}$ (segment aa' in Fig. 10).

The diagram of Fig. 11 summarizes the relationships between the deepening of the groove in the rock mass (increase of $Z$ ), the change in the $\sigma_{\mathrm{xx}}(\mathrm{Z})$ stress component acting within the volume of rock to be removed and the cutting rate $\mathrm{CR}\left(\sigma_{\mathrm{xx}}\right)$.

The figure shows three succeeding steps of a cut performed along the $y z$ plane in a rock subjected to compressive stress.

STEP1. The initial value of the normal stress component is $\sigma_{\mathrm{xx} 0}$, which is also the Efficiency limit stress $\left(\mathrm{E} \sigma_{\mathrm{xx}}\right)$ for the first preset value of the cutting rate $\mathrm{CR} 1\left(\mathrm{E} \sigma_{\mathrm{xx}}(\mathrm{CR} 1)=\right.$ $\left.\sigma_{\mathrm{xx} 0}\right)$. As the cut proceeds from $\mathrm{Z}_{0}$ to $\mathrm{Z}_{1}$, the compressive stress component $\sigma_{x x}$ progressively increases up to the value $\sigma_{\mathrm{xx} 1}$, which corresponds to the Sustainability Limit Stress $\left(\mathrm{S} \sigma_{\mathrm{xx}}\right)$ for the first preset value of the cutting rate (CR1).

STEP2. The cutting rate is reduced to CR2, as the new value $\sigma_{\mathrm{xx} 1}$ of the compressive stress is the $\mathrm{E} \sigma_{\mathrm{xx}}$ for CR2 $\left(E \sigma_{x x}(C R 2)=\sigma_{x x 1}\right)$. The cut proceeds from $Z_{1}$ to $Z_{2}$, while the compressive stress reached the value $\sigma_{\mathrm{xx} 2}$, which is the $\mathrm{S} \sigma_{\mathrm{xx}}$ for $\mathrm{CR}=\mathrm{CR} 2$.

STEP3. The cutting rate is further reduced to CR3, as the new value of the compressive stress $\left(\sigma_{\mathrm{xx} 2}\right)$ is the $E \sigma_{\mathrm{xx}}$ for CR3 $\left(E \sigma_{x x}(\mathrm{CR} 3)=\sigma_{\mathrm{xx} 2}\right)$. The cut proceeds up to the end $(\mathrm{Z}=\mathrm{Z} 3$ ) with $\mathrm{CR}=\mathrm{CR} 3$. 
Fig. 11 Schematic representation of the relationships between the development of the cut (increase of $Z$ ), the intensification of the $\sigma_{\mathrm{xx}}(\mathrm{Z})$ and the cutting rate $\mathrm{CR}^{*}\left(\sigma_{\mathrm{xx}}\right)$

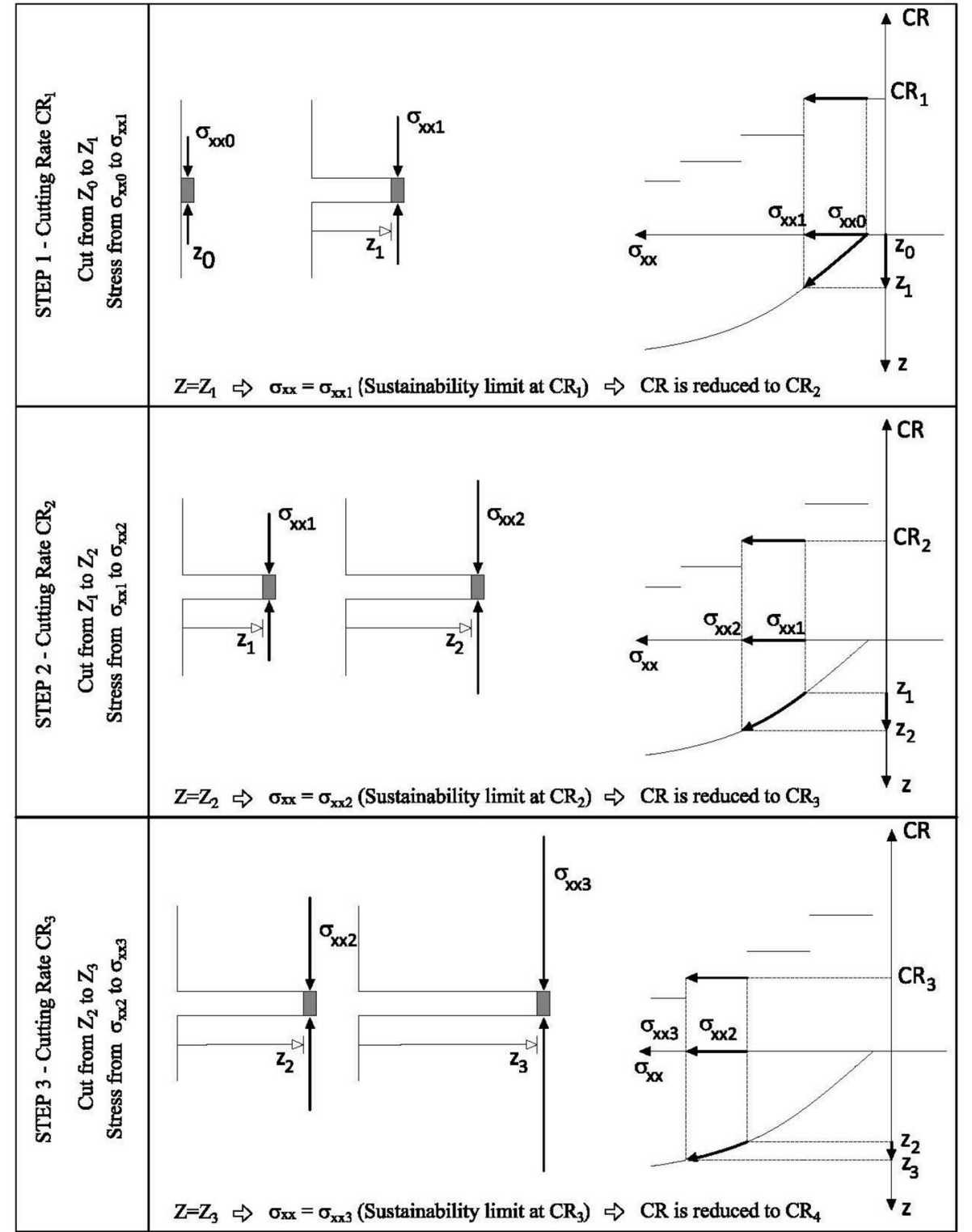

\subsection{Correlations and Comprehensive Results Link}

The experimental research hereby discussed allowed the estimation of the Sustainability limit stress $S \sigma_{x x}$ for the compressed samples and the Efficiency limit stress $E \sigma_{x x}$ for the tense samples. The comprehensive experimental plan is reported in Table 10, with the values of $C R^{*}$ and the correspondent limit values of $E \sigma_{x x}$ and $S \sigma_{x x}$. For the three generation pressures under investigation, Fig. 12 shows the interpolating curves of the experimental results, which clearly highlight the influence of the state of stress on the cutting rate: in compressed rocks, the increase of the absolute value of $\sigma_{x x}$ determines a reduction of the maximum $C R$; in tense rocks, the increase of the absolute value of $\sigma_{x x}$ determines an increase of the maximum $C R$. According to the cutting test, the $C R$ obtainable in unloaded samples of granite $\left(0.63 \mathrm{~m}^{2} / \mathrm{h}\right)$ is halved $\left(0.30 \mathrm{~m}^{2} / \mathrm{h}\right)$ when the compressive stress increases up to $-26.8 \mathrm{MPa}$ and becomes $1 \mathrm{~m}^{2} / \mathrm{h}$ when the tensile stress reaches $+8 \mathrm{MPa}$.

The mean slope of the interpolating curves $\left(\Delta \mathrm{CR} / \Delta \sigma_{\mathrm{xx}}\right)$ in Fig. 12 also proves that the influence of the state of stress on CR is less relevant the greater the energy of the jet (higher generation pressure) and becomes negligible with generation pressure of $200 \mathrm{MPa}$. Table 11 reports the value of the mean slope $\Delta \mathrm{CR} /$ $\Delta \sigma_{\mathrm{xx}}$ for each generation pressure in the experimental plan.

The results confirm the general relationship between CR and the state of stress, which has already been discussed in previous studies, as well as the role of the generation 
Table 10 Comprehensive experimental plan and results of test and numerical analysis $-\mathrm{p}=100 \mathrm{MPa}$

\begin{tabular}{|c|c|c|c|c|c|c|c|}
\hline Test sample & $\begin{array}{l}\text { Cutting } \\
\text { rate }(\mathrm{CR} *) \\
\left(\mathrm{m}^{2} / \mathrm{h}\right)\end{array}$ & $\begin{array}{l}\text { Measured } \\
\text { limit depth } \\
(\mathrm{mm})\end{array}$ & Model & $\begin{array}{l}\text { Lateral load } \\
(\mathrm{kN})\end{array}$ & $\begin{array}{l}\text { Simulated } \\
\text { limit condi- } \\
\text { tion } \\
\text { (depth of } \\
\text { groove } \\
(\mathrm{mm}) \text { ) }\end{array}$ & SubModel & $\begin{array}{l}\mathrm{S} \sigma_{\mathrm{xx}}(-) \\
\mathrm{E} \sigma_{\mathrm{xx}}(+) \\
(\mathrm{MPa})\end{array}$ \\
\hline \multirow[t]{3}{*}{$\mathrm{C} 1, \mathrm{a}, \mathrm{b}, \mathrm{c}$} & 0.45 & 25 & \multirow[t]{3}{*}{ CM1 } & \multirow[t]{3}{*}{250} & 25 & $\mathrm{CM} 1 \alpha$ & -11.6 \\
\hline & 0.36 & 35 & & & 35 & CM1 $\beta$ & -15.0 \\
\hline & 0.30 & 60 & & & 60 & CM1 $\chi$ & -26.8 \\
\hline \multirow[t]{3}{*}{$\mathrm{C} 2 \mathrm{a}, \mathrm{b}, \mathrm{c}$} & 0.45 & 8 & \multirow[t]{3}{*}{ CM2 } & \multirow[t]{3}{*}{500} & 8 & $\mathrm{CM} 2 \alpha$ & -12.6 \\
\hline & 0.36 & 15 & & & 15 & $\mathrm{CM} 2 \beta$ & -15.4 \\
\hline & 0.45 & 25 & & & 25 & $\mathrm{CM} 2 \chi$ & -22.4 \\
\hline \multirow[t]{2}{*}{$\mathrm{C} 1 \mathrm{a}^{\prime}, \mathrm{b}^{\prime}, \mathrm{c}^{\prime}$} & 1.30 & 23 & \multirow[t]{2}{*}{ CM1' } & \multirow[t]{2}{*}{250} & 23 & CM1 $\alpha^{\prime}$ & -11.0 \\
\hline & 1.1 & 61 & & & 61 & CM1 $\beta$ ' & -28.0 \\
\hline \multirow[t]{2}{*}{ C2 a', b', c' } & 0.90 & 44 & \multirow[t]{2}{*}{ CM2' } & \multirow[t]{2}{*}{500} & 44 & $\mathrm{CM} 2 \alpha^{\prime}$ & -44.5 \\
\hline & 0.83 & 64 & & & 64 & CM $2 \beta$ ' & -63.0 \\
\hline \multirow[t]{2}{*}{ C1a", b", c"' } & 1.79 & 40 & \multirow[t]{2}{*}{ CM1' } & \multirow[t]{2}{*}{250} & 40 & CM1 $\alpha^{\prime \prime}$ & -18.0 \\
\hline & 1.78 & 65 & & & 65 & CM1 $\beta$, & -32.0 \\
\hline \multirow[t]{2}{*}{ C2a', b', c', } & 1.75 & 65 & \multirow[t]{2}{*}{ CM2' } & \multirow[t]{2}{*}{500} & 65 & CM2 $2 \alpha^{\prime \prime}$ & -65.0 \\
\hline & 1.65 & 82 & & & 82 & CM2 $\beta$, & -80.0 \\
\hline \multirow[t]{2}{*}{ T1a,b,c } & 0.69 & 5 & \multirow[t]{2}{*}{ TM1 } & \multirow[t]{2}{*}{50} & 5 & TM1 $\alpha$ & +2.5 \\
\hline & 0.73 & 30 & & & 30 & TM1 $\beta$ & +3.2 \\
\hline \multirow[t]{2}{*}{ T2a,b,c } & 0.84 & 30 & \multirow[t]{2}{*}{ TM2 } & \multirow[t]{2}{*}{100} & 30 & TM $2 \alpha$ & +6.4 \\
\hline & 1.00 & 50 & & & 50 & TM $2 \beta$ & +8.0 \\
\hline
\end{tabular}

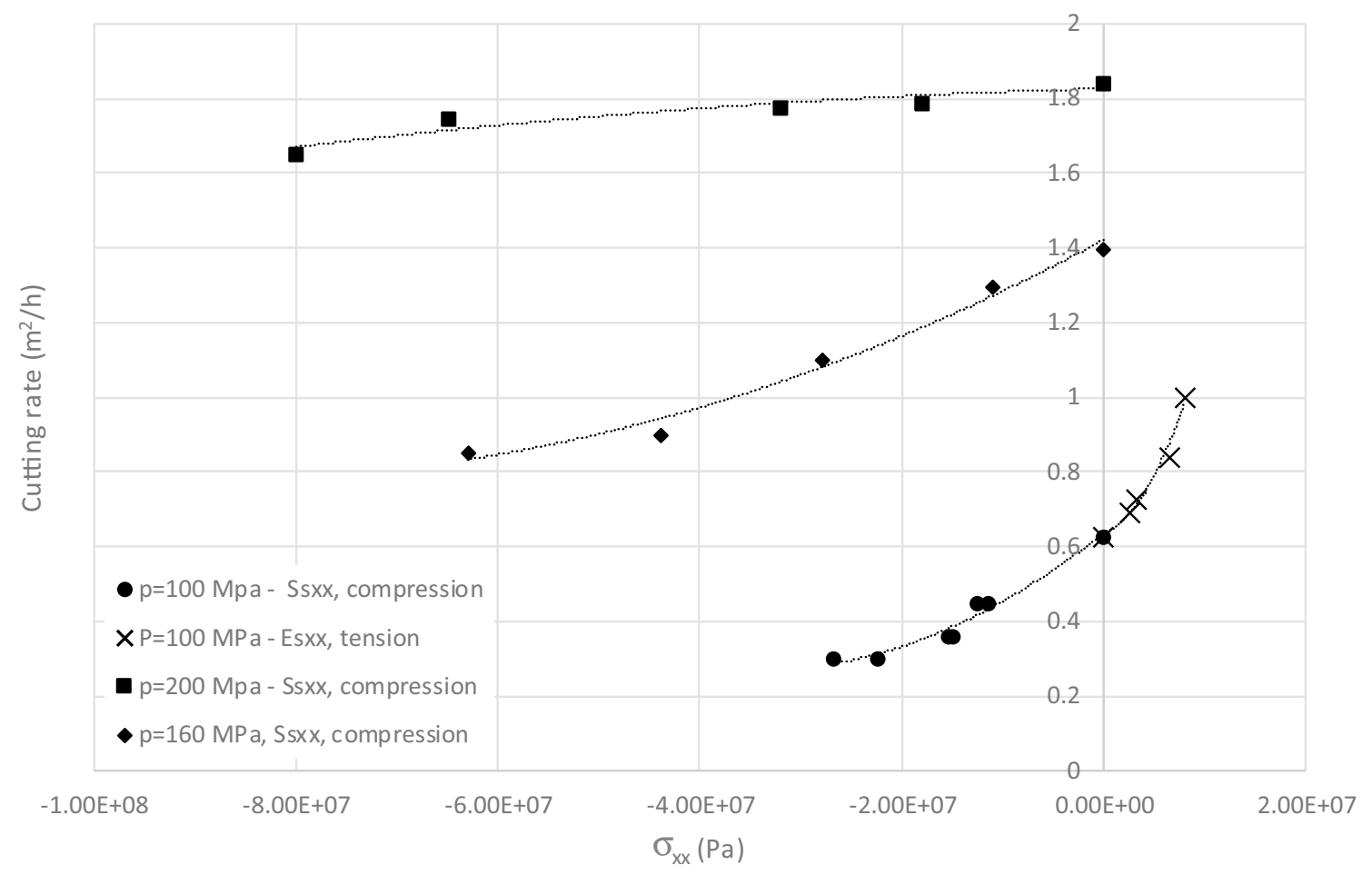

Fig. 12 Comprehensive results and interpolating curves for the three values of the generation pressure 
Table 11 Mean slope of the interpolating curves $\sigma \mathrm{xx}-\mathrm{CR}^{*}$ in Fig. 10

\begin{tabular}{ll}
\hline $\begin{array}{l}\text { Generation pres- } \\
\text { sure } \\
(\mathrm{MPa})\end{array}$ & $\begin{array}{l}\Delta \mathrm{CR} / \Delta \sigma_{\mathrm{xx}} \\
\left(\mathrm{m}^{2} / \mathrm{h}\right) / \mathrm{MPa}\end{array}$ \\
\hline 200 & $-1.10 \mathrm{E} 3$ \\
160 & $-8.4 \mathrm{E} 3$ \\
100 & $-1.4 \mathrm{E} 2$ \\
\hline
\end{tabular}

pressure (Ciccu 1998; Ciccu 2003). They also clarify the concepts of the Efficiency and Sustainability Limit Stress in the step function that approximates the conceptual continuous $C R$-Stress function.

\section{Conclusions}

To assess the effect of the state of stress on the cutting rate $C R$, laboratory tests were performed with an oscillating water jet machine on granite samples of Rosa beta subjected to a static load. The stress distribution in the layer of rock to be removed was modeled with the FLAC code. The results confirmed that the increase of the state of stress due to the slot's advancement causes the reduction of the maximum cutting rate in compressed rocks and the increase in rocks subjected to tensile stress.

Starting from a conceptual model, which theoretically explains the relationship between $C R$ and the stress component $\sigma_{x x}$, a step function was defined that indicates the ranges $\Delta \sigma_{x x}$ where predefined values of the cutting rate $\left(C R^{*}\right)$ are workable: the sustainability limit stress $S \sigma_{x x}$ and the effciency limit stress $E \sigma_{x x}$ are the limits of those ranges. The sustainability limit stress was found for the granite samples subjected to compressive stress and the efficiency limit stress for those subjected to tensile stress. The test also proved the influence of the state of stress on the water jet cutting performance to be less relevant the greater the energy of the jet (higher generation pressure).

The implications of the research hereby discussed become apparent when considering the industrial implementation of the water jet technology to the extraction of granite in underground environments. In fact, the knowledge of the $\sigma_{\mathrm{xx}}-C R$ relationship allows planning the cutting sequence, so that the development of the state of stress within the rock massif is that which maximizes the average speed of the entire operation (i.e., minimizes the time required to isolate commercial blocks).

It should be noted that the overall outcome of the study has a general conceptual value (i.e., influence of $\sigma_{x x}$ on $C R$ and effect of the water jet energy); nonetheless, the industrial application requires the experimental definition of the step function $\sigma_{\mathrm{xx}}-C R^{*}$ for the specific operating condition under exam: type of rock, cutting technology and operating parameters.
Acknowledgements This research was supported by the National University Consortium on Geoengineering (CINIGeo)-Italy

Funding Open access funding provided by Università degli Studi di Cagliari within the CRUI-CARE Agreement.

\section{Declarations}

Conflict of interest The authors declare that they have no conflicts of interest.

Open Access This article is licensed under a Creative Commons Attribution 4.0 International License, which permits use, sharing, adaptation, distribution and reproduction in any medium or format, as long as you give appropriate credit to the original author(s) and the source, provide a link to the Creative Commons licence, and indicate if changes were made. The images or other third party material in this article are included in the article's Creative Commons licence, unless indicated otherwise in a credit line to the material. If material is not included in the article's Creative Commons licence and your intended use is not permitted by statutory regulation or exceeds the permitted use, you will need to obtain permission directly from the copyright holder. To view a copy of this licence, visit http://creativecommons.org/licenses/by/4.0/.

\section{References}

Ashmole I, Motloung M (2008) Dimension stone: the latest trends in exploration and production technology. the Southern African Institute of Mining and Metallurgy: 35-70.

Averin E (2017) Universal method for the prediction of abrasive waterjet performance in mining. Engineering: 888-891.

Babitha RH, Shadakshara Swamy N (2007) Impact of crushing and quarrying on vegetation. J Industrial Pollution Control: 231-237.

Bortolussi A, Ciccu R, Manca PP, Massacci G A systematic study of granite slotting with water jets. In Jet cutting Technology, di A. Lichtarowicz. Kluwer Acad. Publ, 1992.

Bortolussi A, Dentoni V, Massacci G (2010) Noise generation in water jet technology. Int J Min Reclamation Environment, 24(2): 180-192.

Ciccu R, Bortolussi A (1998) «Waterjet in dimensional stone quarrying,» In Waterjet applications in construction engineering, di A:W: Momber, 289-305. Balkema, Rotterdam

Ciccu R, Fiamminghi A (1996) Quarrying granite underground is now feasible with waterjet. 13th Int. Conf. on Jetting Technology, Cagliari: BHRg.

Ciccu R, Grosso B, Bortolussi A (2013) Effect of the stress state on waterjet performance in rock slotting. 23rd International Mining Congress and Exhibition of Turkey, IMCET 2013. Antalya; Turkey, 455-461.

Dentoni V, Grosso B, Massacci G, Soddu GP Visual impact evaluation of mines and quarries: the updated Lvi method. Environ Earth Sci.

Fornaro M, Mancini R, Pelizza S, Stragiotti L (1992) Underground production of marble in Italy: technology, economy and environmental constraints. XV World Mining Congress. Madrid. pp 573-582.

Fugiel A, Burchart-Korol Dorota, Czaplicka-Kolarz Krystyna, Adam Smolinski (2017) Environmental impact and damage categories caused by air pollution emissions from mining and quarrying sectors of European countries. Journal of Cleaner Production: $159-168$. 
Hood M. «The use of water jet rock excavation in , pp.» In Comprehensive rock Engineering, Volume 4, 229-260,. Pergamon Press, 1993.

Hood M, Nordlund R, Thimons E (1990) A study of rock erosion using high-pressure water jets. International Journal of Rock Mechanics and Mining Sciences and: 77-86.

Rehbinder G (1977) Slot cutting in rock with a high speed water jet. International Journal of Rock Mechanics and Mining Sciences and,: 229-234.

Reichman JM, Cheung JB (1978) An Oscillating Water Jet DeepKerfing Technique. Int J Rock Mech Min Sci: 135-144.
Stoxreiter T, Martin A, Teza D, Galler R (2018) Hard rock cutting with high pressure jets in various ambient pressure regimes. Int J Rock Mech Min Sci: 179-188.

Summers DA, Yao J, Yazicy S (1997) Basic Consideration in Water Jet Cutting. In: Proc. 1st Asian Conf. on Recent Advances in Jetting Technology. Singapore, 93-100.

Publisher's Note Springer Nature remains neutral with regard to jurisdictional claims in published maps and institutional affiliations. 